\title{
Determinants of countermovement jump performance: a kinetic and kinematic analysis
}

\author{
${ }^{1}$ Stuart McErlain-Naylor, ${ }^{1}$ Mark King, ${ }^{1}$ Matthew T G Pain \\ ${ }^{1}$ School of Sport, Exercise and Health Sciences, Loughborough University, Leicestershire, LE11 3TU, UK
}

\begin{abstract}
This study aimed to investigate the contributions of kinetic and kinematic parameters to inter-individual variation in countermovement jump (CMJ) performance. Two-dimensional kinematic data and ground reaction forces during a CMJ were recorded for 18 males of varying jumping experience. Ten kinetic and eight kinematic parameters were determined for each performance, describing peak lower-limb joint torques and powers, concentric knee extension rate of torque development, and CMJ technique. Participants also completed a series of isometric knee extensions to measure rate of torque development and peak torque. CMJ height ranged from $0.38-0.73 \mathrm{~m}$ (mean $0.55 \pm 0.09$ $\mathrm{m}$ ). CMJ peak knee power, peak ankle power, and take-off shoulder angle explained $74 \%$ of this observed variation. CMJ kinematic (58\%) and CMJ kinetic $(57 \%)$ parameters explained a much larger proportion of the jump height variation than the isometric parameters $(18 \%)$, suggesting that coachable technique factors and the joint kinetics during the jump are important determinants of CMJ performance. Technique, specifically greater ankle plantar-flexion and shoulder flexion at take-off (together explaining 58\% of the CMJ height variation), likely influences the extent to which maximal muscle capabilities can be utilised during the jump.
\end{abstract}

Keywords: countermovement jump, kinetics, kinematics, technique, rate of torque development

\section{INTRODUCTION}

The countermovement jump (CMJ) is a key performance requirement in many sports. Research has shown positive relationships between lower-limb strength and power measures and CMJ performance (Ashley \& Weiss, 1994; Nuzzo, McBride, Cormie, \& McCaulley, 2008; Sheppard et al., 2008; Wisløff, Castagna, Helgerud, Jones, \& Hoff, 2004). However, further research is needed to explain quantitatively the relative contributions of kinetic and kinematic variables to this movement. Of the kinetic determinants, greater rate of force or torque development has frequently been associated with increased CMJ performance (De Ruiter, van Leeuwen, Heijblom, Bobbert, \& De Haan, 2006; Marcora \& Miller, 2000; McLellan, Lovell, \& Gass, 2011; Thompson et al., 2013). Both rate of force development and rate of torque development measure the capabilities of skeletal muscle to rapidly generate muscle forces and for the purposes of the present study will be referred to as rate of torque development. Furthermore, it seems that the maximum force-dependent, post-50 $\mathrm{ms}$, rate of torque development is more strongly related to $\mathrm{CMJ}$ height than the earlier, neurally-mediated rate of torque development (Tillin, Pain, \& Folland, 2013).

There are discrepancies among the results of the few studies investigating ankle, knee and hip joint contributions during the CMJ. Hubley and Wells (1983) found the greatest contributor to be the knee joint (49\% of the total positive work), whilst Fukashiro and Komi (1987) found it to be the hip joint (51\%). More recently, Vanezis and Lees (2005) obtained values (30\% at the knee and $42 \%$ at the hip) that were in closer agreement with Fukashiro and Komi (1987) than with Hubley and Wells (1983). A novel finding by Vanezis and Lees (2005) was a negative relationship between hip work and knee work, indicating a technique difference between participants. The authors suggested that this difference could account for 
previous discrepancies in the literature, implying that technique determines the relative contribution of different lower-limb joints. The inclusion of an arm swing increased jump height by approximately $10 \mathrm{~cm}$, supporting previous arm swinginduced performance improvements (Feltner, Fraschetti, \& Crisp, 1999; Shetty \& Etnyre, 1989). Likely contributors to this effect include the increase in work done at the hip joint (Hara, Shibayama, Takeshita, \& Fukashiro, 2006; Lees, Vanrenterghem, \& De Clercq, 2004) and maximised pre-takeoff mass centre displacement (Cheng, Wang, Chen, Wu, \& Chiu, 2008; Harman, Rosenstein, Frykman, \& Rosenstein, 1990; Payne, Slater, \& Telford, 1968) in jumps with an arm swing. Simulation studies of squat jumping show the augmented hip work to be due to a slowing of hip extension enabling the musculature to work on a more favourable region of the force-velocity curve (Blache \& Monteil, 2013; Cheng et al., 2008; Domire \& Challis, 2010). Approximately one third of the arm swing related performance improvement results from the work and energy induced at the shoulder joint (Domire \& Challis, 2010).

Countermovement depth has also been linked to CMJ performance. Moran and Wallace (2007) found that increasing the knee joint range of motion from $70^{\circ}$ to $90^{\circ}$ resulted in a $17 \%$ improvement in CMJ height. Similarly, high ankle dorsi-flexion range of motion has been shown to contribute to CMJ performance in men but not women (Georgios, Fotis, Thomas, Vassilios, \& Iraklis, 2007). Simulation studies have shown an increase in squat depth to improve squat jump performance due to an increase in time to develop joint torques (Bobbert, Casius, Sijpkens, \& Jaspers, 2008; Domire \& Challis, 2007). Proposed mechanisms for the benefit of the countermovement phase in a CMJ include the development of active state prior to concentric action (Bobbert, Gerritsen, Litjens, \& van Soest, 1996; Bobbert \& Casius, 2005), tendon elastic recoil (Alexander, 1995), and the enhancement of subsequent force following muscle stretch (Edman, Elzinga \& Noble, 1978).

Few researchers have compared kinetic and kinematic CMJ determinants. Vanezis and Lees (2005) concluded that kinematic technique factors were less important than muscle capabilities, although their technique analysis was limited to the timing of the lowest vertical mass centre position and the use (or not) of an arm swing. An increase in strength does not always result in a subsequent performance improvement (Clutch, Wilton, McGown, \& Bryce, 1983), perhaps due to the need to adapt coordination following strength gains (Bobbert \& van Soest, 1994). Supporting the importance of appropriate technique utilisation, Luhtanen and Komi (1978) reported that well-trained participants were able to utilise only $76 \%$ of the available mechanical energy during a CMJ but that optimal coordination could increase this to $84 \%$. It is evident that in order to gain a broad understanding of the determinants of CMJ performance, it is necessary to study both kinetic and kinematic variables.

If the findings of this study are to be practically applicable when considering progression from poor to good countermovement jumping ability then it is important that variables contributing to the difference between good and poor jumpers are identified. This necessitates the recruitment of a heterogeneous ability range to the sample population so that the effects of variability in each of the kinetic and kinematic variables can be observed. The purpose of the present study is therefore to quantify the relative contributions of these factors in order to identify the most important determinants of CMJ height.

\section{METHODS}

Eighteen physically active males $(21.2 \pm 2.2$ years, $1.80 \pm 0.08 \mathrm{~m}, 78.1 \pm 9.2$ $\mathrm{kg}$, mean $\pm S D$ ) participated in this investigation. Participants with large variation in 
jumping experience were selected so as not to distort the importance of individual variables. The testing procedures were explained to each participant and informed consent was obtained in accordance with the Loughborough University Ethical Advisory Committee.

Participants attended two laboratory testing sessions: 1) isometric knee extension measurement; 2) anthropometric and CMJ measurement. They were required to refrain from strenuous physical activity for 36 hours prior to each session. The knee extensor contractile properties of the dominant leg were tested using a dynamometer (Con-Trex; CMV Aargau, Switzerland; hip angle 100\%; frequency 512 $\mathrm{Hz}$ ). Following dynamic stretching and submaximal warm up trials of incremental intensity, isometric unilateral knee extension torque was measured at five angles $\left(15^{\circ}, 30^{\circ}, 45^{\circ}, 60^{\circ}, 75^{\circ} ; 0^{\circ}\right.$ indicated a fully extended leg) in a randomised order. Two trials were recorded at each angle, separated by 2 min rest: a $5 \mathrm{~s}$ maximal voluntary contraction; then a measure of rate of torque development, with the participant instructed to increase their knee extension torque as fast as possible (Sahaly, Vandewalle, Driss, \& Monod, 2001). The participants rested for $3 \mathrm{~min}$ between each knee angle. The peak isometric knee extension torque was identified as the highest of the angle-specific peak torques. The rate of torque development trial at the angle corresponding to peak isometric torque was used to obtain the rate of change of joint torque in 50 ms intervals $\left(R T D_{0-50}, R T D_{50-100}, R T D_{100-150}\right)$ from 0$150 \mathrm{~ms}$ after the onset of contraction (identified manually; Tillin, Jimenez-Reyes, Pain, \& Folland, 2010). This enabled the investigation of the earlier agonist neural drive dominated and later maximal voluntary torque dominated rate of torque development (Andersen \& Aagaard, 2006; Tillin, Pain, \& Folland, 2012). All isometric parameters were normalised to body mass.

For the CMJ measurement, thirty-eight $14 \mathrm{~mm}$ retro-reflective markers were attached to each participant, positioned over bony landmarks. The metatarsophalangeal, ankle, knee, shoulder, elbow and wrist joint centres were calculated from a pair of markers placed across the joint so that their mid-point coincided with the joint centre, similarly to Ranson, King, Burnett, Worthington, and Shine (2009). The centre of the neck was defined as the midpoint between two parkers positioned over the sternoclavicular notch and the $\mathrm{C} 7$ vertebra. The centre of the head was defined as the average position of four markers and the hip joint centres were calculated from four markers placed over the left and right anterior and posterior superior iliac spine (Davis, Õunpuu, Tyburski, \& Gage, 1991). Participants were given the chance to perform a self-selected warm-up and to practice before performing three maximal CMJs using a natural technique of their selection, including arm swing. They were permitted to rest between trials for as long as they felt necessary, with a minimum rest period of $15 \mathrm{~s}$ imposed (Read \& Cisar, 2001). Trials were recorded using a 17 camera ( $\left.\mathrm{M}^{2} \mathrm{MCam}\right)$ Vicon Motion Analysis System (OMG Plc, Oxford, UK) operating at $480 \mathrm{~Hz}$. Ground reaction forces were measured using an AMTI force platform $(600 \times 400 \mathrm{~mm}, 960 \mathrm{~Hz})$.

The CMJs were manually labelled and processed and all data were synchronised in Vicon's software. Two-dimensional position data were used, with the assumption of negligible movement in the medio-lateral plane. All joint centre trajectories were filtered using a recursive fourth-order low-pass Butterworth filter with a cut-off frequency of $6 \mathrm{~Hz}$ determined based on a residual analysis and qualitative evaluation of the data (Winter, 1990). Unilateral joint centre positions were assumed to represent the bilateral location and the errors in jump height and peak joint torques caused by this assumption were calculated for one participant. 
These were found to be less than $1 \%$, with the error in mass centre displacement and joint torques remaining small throughout the movement.

Subject-specific segmental inertia parameters were computed from anthropometric measurements using Yeadon's (1990) geometric inertia model of the human body. The average centre of mass height during the approximately $2 \mathrm{~s}$ period of stationary standing prior to the jump was defined as zero displacement and thus the CMJ height was determined as the maximum vertical mass centre displacement, with the highest jump for each participant used for further analysis. Inverse dynamics was used to obtain body mass normalised peak ankle, knee and hip net joint torques and powers, with extension torques presented as positive. In order to provide methodological consistency with the isometric rate of torque development and facilitate the investigation of different time periods during knee extension, CMJ rate of torque development was computed from $0-200 \mathrm{~ms}$ of knee extension in $50 \mathrm{~ms}$ intervals (CMJ RTD $D_{0-50}$, CMJ RTD ${ }_{50-100}$, CMJ RTD ${ }_{100-150}$, and CMJ RTD $\left.{ }_{150-200}\right)$. Eight kinematic parameters were also defined: minimum absolute joint angles and those at take-off for the ankle, knee, hip, and shoulder. Shoulder extension beyond the line of the greater trochanter to glenohumeral joint was defined as negative, with flexion forwards from this line positive.

All statistical analyses were performed within SPSS v.20 (SPSS Corporation, USA). To address the aim of the study and identify which of the isometric, CMJ kinematic, and CMJ kinetic (independent) variables best explained the variation in CMJ height (dependent variable), forwards stepwise linear regressions were used. Predictor variables included in these three regression models were put forward as 'candidate' variables to an overall regression model. Scatterplot and Pearson Product Moment Correlation analyses revealed a significant $(r=0.68, P<0.01)$ quadratic relationship between $C M J R_{0-50}$ and $C M J$ height and thus an exponentiation transformation was performed on CMJ $R T D_{0-50}$, raising each value to the power of two prior to its inclusion in the linear regression analyses. The requirement for the inclusion of a parameter in the regression equations was $\mathrm{P}<$ 0.05 . Similarly, regression models were rejected if coefficient $95 \%$ confidence intervals included zero or if correlations, tolerance statistics, or variance inflation factors showed any evidence of multicollinearity (Bowerman \& O'Connell, 1990; Draper \& Smith, 1998; Field, 2013; Menard, 1995; Myers, 1990). To confirm the normality of the standardised residuals in the regression models Shapiro-Wilk tests for normality were performed. The P-values ranged from 0.22 to 0.88 indicating no evidence against the assumption of normality of the residuals. The percentage of variance in the dependent variable (CMJ height) explained by the independent variable(s) in a regression was determined by Wherry's (1931) adjusted $R$ squared value. This represents an attempt to estimate the proportion of variance that would be explained by the model had it been derived from the population (young physically active males) from which the sample was taken. To overcome the potential limitation of stepwise regressions relying on a single best model, the explained variance for all possible regressions with the same number of predictor variables as the stepwise solution were determined for comparison. Pearson Product Moment correlation was used to establish relationships, with a $\mathrm{P}$-value $<0.05$ indicating statistical significance.

\section{RESULTS}

The eighteen males participating in this study achieved CMJ heights of 0.38 $0.73 \mathrm{~m}$ (mean $0.55 \pm 0.09 \mathrm{~m}$ ). There was substantial variation in the isometric 
parameters (Table I) with a mean peak isometric knee extension torque of $3.62 \pm$ $0.68 \mathrm{~N} \cdot \mathrm{m} \cdot \mathrm{kg}^{-1}$. Of the CMJ kinematic parameters (Table I), the shoulder showed the largest variation, indicating a technique difference at this joint. Mean peak powers at the ankle, knee, and hip were $18.00 \pm 4.20 \mathrm{~W} \cdot \mathrm{kg}^{-1}, 22.02 \pm 4.94 \mathrm{~W} \cdot \mathrm{kg}^{-1}$, and $9.83 \pm$ $3.54 \mathrm{~W} \cdot \mathrm{kg}^{-1}$ respectively (Table I). The mean concentric CMJ rate of torque development was negative for all four $50 \mathrm{~ms}$ intervals.

Table I. Summary of parameters

\begin{tabular}{|c|c|c|c|c|c|}
\hline $\begin{array}{l}\text { isometric } \\
\text { parameters }\end{array}$ & $\underset{S D}{\operatorname{mean}} \pm$ & $\begin{array}{l}\text { CMJ kinetic } \\
\text { parameter }\end{array}$ & mean \pm SD & $\begin{array}{l}\text { CMJ kinematic } \\
\text { parameter }\end{array}$ & $\underset{S D}{\operatorname{mean}} \pm$ \\
\hline $\begin{array}{l}\text { peak torque } \\
\left(\mathrm{N} \cdot \mathrm{m} \cdot \mathrm{kg}^{-1}\right)\end{array}$ & $\begin{array}{l}3.62 \pm \\
0.68\end{array}$ & PT ankle $\left(\mathrm{N} \cdot \mathrm{m} \cdot \mathrm{kg}^{-1}\right)$ & $2.79 \pm 0.40$ & $\begin{array}{l}\text { minimum ankle angle } \\
\left({ }^{\circ}\right)\end{array}$ & $84 \pm 9$ \\
\hline $\begin{array}{l}\mathrm{RTD}_{0-50} \\
\left(\mathrm{~N} \cdot \mathrm{m} \cdot \mathrm{kg}^{-1} \cdot \mathrm{s}^{-1}\right)\end{array}$ & $\begin{array}{l}11.67 \pm \\
8.12\end{array}$ & PT knee $\left(\mathrm{N} \cdot \mathrm{m} \cdot \mathrm{kg}^{-1}\right)$ & $3.31 \pm 0.62$ & $\begin{array}{l}\text { minimum knee angle } \\
\left({ }^{\circ}\right)\end{array}$ & $81 \pm 16$ \\
\hline $\begin{array}{l}\mathrm{RTD}_{50-100} \\
\left(\mathrm{~N} \cdot \mathrm{m} \cdot \mathrm{kg}^{-1} \cdot \mathrm{s}^{-1}\right)\end{array}$ & $\begin{array}{l}18.96 \pm \\
7.92\end{array}$ & PT hip $\left(\mathrm{N} \cdot \mathrm{m} \cdot \mathrm{kg}^{-1}\right)$ & $2.20 \pm 0.44$ & minimum hip angle $\left(^{\circ}\right)$ & $75 \pm 15$ \\
\hline \multirow[t]{7}{*}{$\begin{array}{l}\mathrm{RTD}_{100-150} \\
\left(\mathrm{~N} \cdot \mathrm{m} \cdot \mathrm{kg}^{-1} \cdot \mathrm{s}^{-1}\right)\end{array}$} & $\begin{array}{l}10.84 \pm \\
5.07\end{array}$ & PP ankle $\left(\mathrm{W} \cdot \mathrm{kg}^{-1}\right)$ & $18.00 \pm 4.20$ & $\begin{array}{l}\text { minimum shoulder } \\
\text { angle }\left(^{\circ}\right)\end{array}$ & $-67 \pm 26$ \\
\hline & & PP knee $\left(\mathrm{W} \cdot \mathrm{kg}^{-1}\right)$ & $22.02 \pm 4.94$ & TO ankle angle $\left(^{\circ}\right)$ & $137 \pm 12$ \\
\hline & & PP hip (W·kg $\left.{ }^{-1}\right)$ & $9.83 \pm 3.54$ & TO knee angle $\left(^{\circ}\right)$ & $174 \pm 14$ \\
\hline & & $\begin{array}{l}\text { CMJ RTD } 0-50 \\
\left(\mathrm{~N} \cdot \mathrm{m} \cdot \mathrm{kg}^{-1} \cdot \mathrm{s}^{-1}\right)\end{array}$ & $-0.93 \pm 6.07$ & TO hip angle $\left(^{\circ}\right)$ & $172 \pm 5$ \\
\hline & & $\begin{array}{l}\text { CMJ RTD }_{50-100} \\
\left(\mathrm{~N} \cdot \mathrm{m} \cdot \mathrm{kg}^{-1} \cdot \mathrm{s}^{-1}\right)\end{array}$ & $-4.75 \pm 8.12$ & TO shoulder angle $\left(^{\circ}\right)$ & $103 \pm 37$ \\
\hline & & $\begin{array}{l}\text { CMJ RTD } \\
\left(\mathrm{N} \cdot \mathrm{m} \cdot \mathrm{kg}^{-1} \cdot \mathrm{s}^{-1}\right)\end{array}$ & $-1.18 \pm 8.15$ & & \\
\hline & & $\begin{array}{l}\text { CMJ RTD }{ }_{150-200} \\
\left(\mathrm{~N} \cdot \mathrm{m}^{\circ} \mathrm{kg}^{-1} \cdot \mathrm{s}^{-1}\right)\end{array}$ & $-0.66 \pm 7.14$ & & \\
\hline
\end{tabular}

Note: CMJ: countermovement jump; $R_{T D} D_{0-50}, R_{T D} D_{5-100}, R_{T D} 100-150, R_{150-200}$ : rate of torque development from 0-50, 50-100, 100-150, 150-200 ms (of concentric knee extension for the CMJ RTD); PT: peak torque; PP: peak power; TO: take-off.

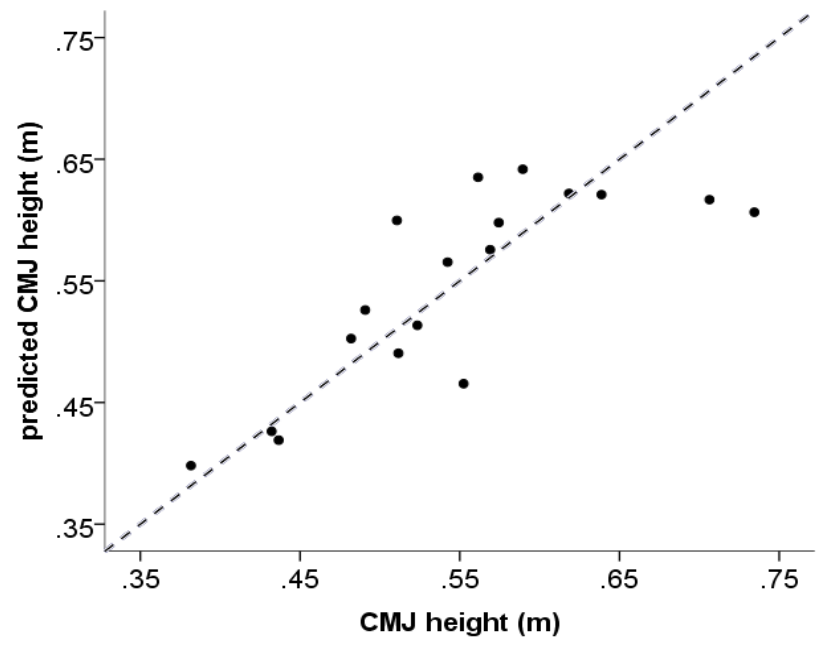

Figure 1. Predicted countermovement jump (CMJ) height against actual CMJ height for the overall three parameter stepwise solution (Table II). $74 \%$ of the variation in CMJ height explained by: CMJ peak knee power; take-off shoulder angle; CMJ peak ankle power. With a higher percentage of the variation in CMJ height explained the closer the data points lie to the dashed line $\mathrm{y}=\mathrm{x}$ (predicted height $=$ actual height). 
Table II. Regression equations predicting countermovement jump height from computed variables using stepwise linear regression

\begin{tabular}{|c|c|c|c|c|c|}
\hline \multirow[b]{2}{*}{ parameter(s) } & \multirow[b]{2}{*}{ coefficient } & \multicolumn{2}{|c|}{$\begin{array}{l}95 \% \text { confidence } \\
\text { intervals }\end{array}$} & \multirow[b]{2}{*}{$\mathbf{P}$} & \multirow[b]{2}{*}{$\begin{array}{l}\text { percentage } \\
\text { explained }\end{array}$} \\
\hline & & $\begin{array}{l}\text { lower } \\
\text { bound }\end{array}$ & $\begin{array}{l}\text { upper } \\
\text { bound }\end{array}$ & & \\
\hline \multicolumn{6}{|l|}{ isometric regression } \\
\hline $\begin{array}{l}\text { peak isometric knee } \\
\text { extension torque }\end{array}$ & 0.064 & 0.002 & 0.127 & 0.045 & 18 \\
\hline \multicolumn{6}{|l|}{$\begin{array}{l}\text { CMJ kinematic } \\
\text { regression }\end{array}$} \\
\hline TO shoulder angle & 0.0016 & 0.0007 & 0.0024 & 0.001 & 58 \\
\hline TO ankle angle & 0.004 & 0.002 & 0.007 & 0.003 & \\
\hline \multicolumn{6}{|l|}{$\begin{array}{l}\text { CMJ kinetic } \\
\text { regression } 1\end{array}$} \\
\hline CMJ peak knee power & 0.011 & 0.005 & 0.017 & 0.002 & 57 \\
\hline CMJ peak ankle power & 0.008 & 0.001 & 0.016 & 0.032 & \\
\hline \multicolumn{6}{|l|}{$\begin{array}{l}\text { CMJ kinetic } \\
\text { regression } 2\end{array}$} \\
\hline CMJ peak knee torque & 0.087 & 0.036 & 0.138 & 0.002 & 57 \\
\hline CMJ peak ankle power & 0.009 & 0.002 & 0.017 & 0.018 & \\
\hline \multicolumn{6}{|l|}{ overall regression } \\
\hline CMJ peak knee power & 0.010 & 0.005 & 0.015 & 0.001 & 74 \\
\hline TO shoulder angle & 0.001 & 0.0004 & 0.002 & 0.005 & \\
\hline CMJ peak ankle power & 0.008 & 0.002 & 0.014 & 0.010 & \\
\hline
\end{tabular}

Note: CMJ: countermovement jump; TO: take-off; CMJ kinetic regression 1: stepwise solution; CMJ kinetic regression 2: alternative solution. $\mathrm{P}<0.05$ indicates a significant relationship.

The best individual predictor of CMJ height was peak power at the knee joint, explaining $44 \%$ of the observed variation $(P<0.01)$. This increased to $74 \%$ with the addition of one CMJ kinematic parameter (take-off shoulder angle) and a further CMJ kinetic parameter (peak ankle power; Figure 1). Higher jumps were associated with greater peak powers at the knee and ankle, and greater shoulder flexion at take-off. The CMJ kinematic regression showed the shoulder angle at take-off to be the greatest kinematic predictor of jump height $\left(R^{2}=0.26, P<0.05\right)$. Greater shoulder flexion and ankle plantar-flexion at take-off predicted greater jump heights (together explaining 58\% of the variation). Two CMJ kinetic parameters (peak knee power and peak ankle power) explained $57 \%$ of the variation (Table II). Increases in these parameters were associated with greater CMJ heights. Further analysis showed that an alternative CMJ kinetic regression model including peak knee torque and peak ankle power also explained $57 \%$ of the variation in jump height.

The peak isometric knee extension torque alone accounted for $18 \%$ of the jump height variation $(\mathrm{P}<0.05$; Table II), with insufficient evidence to support the addition of any further isometric parameters to the regression equation (i.e. $P>0.05$ ). The correlation between peak isometric knee extension torque and CMJ peak knee power was non-significant $(r=0.267 ; P=0.142)$, with only $7 \%$ of the variation in peak knee power explained by peak isometric torque. 


\section{DISCUSSION}

The present study has identified the parameters that best explain CMJ height. In particular, $74 \%$ of the performance variation can be explained using just three parameters: CMJ peak knee power; take-off shoulder angle; and CMJ peak ankle power. Two CMJ kinematic parameters (take-off shoulder angle; and take-off ankle angle) explained $58 \%$ of the jump height variation, whilst two CMJ kinetic parameters (peak knee power or peak knee torque; and peak ankle power) and one isometric parameter (peak isometric knee extension torque) explained $57 \%$ and $18 \%$ respectively.

The inclusion of peak power at the knee and ankle joints in the overall regression model supports previous claims that CMJ performance is positively associated with lower-limb power (Ashley \& Weiss, 1994; Nuzzo et al., 2008; Sheppard et al., 2008; Vanezis \& Lees, 2005). The work-energy-power relationship makes it inevitable that greater joint powers result in more positive work done and so greater total body kinetic energy and mass centre vertical velocities at take-off. As an indicator of maximal capabilities of the knee extensor musculature, a greater peak isometric knee extension torque enables greater joint torques and powers to be produced during the CMJ. However, whilst the inclusion of peak isometric torque in the isometric regression furthers the existing evidence for a relationship between strength and CMJ height (Ashley \& Weiss, 1994; Sheppard et al., 2008; Wisløff et al., 2004), CMJ peak knee power explained a much greater proportion of the performance variation (44\% versus $18 \%$ ). Similarly, Young, Wilson, and Byrne (1999) showed that CMJ height is more closely related to measures of speedstrength qualities than maximum strength. Indeed the low $R^{2}(0.07)$ and lack of significant correlation between body mass normalised peak isometric torque and CMJ peak knee power variables suggest it is not maximal muscle strength that causes the strong relationships between CMJ kinetic variables and jump height. Given that the isometric parameters explained only $18 \%$ of the variation and $58 \%$ can be explained by CMJ kinematic parameters it seems likely that technique (kinematic parameters) determines the extent to which the maximal muscle capabilities (isometric parameters) can be utilised during the jump (to produce the CMJ kinetic parameters). Indeed, Bobbert and van Soest (1994) showed that an increase in muscle strength only improves CMJ performance if technique is adapted to the specific muscle capabilities. Thus, both the technique used and the joint kinetics during the jump are likely important determinants of CMJ height in the current sample of participants, where jumping ability varied greatly (from $0.38-0.73 \mathrm{~m}$ ). Experienced jumpers would be expected to use similar, close to optimal, techniques and thus muscle capabilities may distinguish between their performances, as reported by Vanezis and Lees (2005).

The lack of significant finding relating to the initial, neutrally-mediated isometric $\mathrm{RTD}_{0-50}$ is in agreement with Tillin et al. (2013) but not De Ruiter et al. (2006). It seems likely that the countermovement phase of the jump diminishes the importance of fast neural activation by enabling the development of an active state prior to the onset of concentric muscle contraction and thus increasing the time available to activate the musculature and to generate extension joint torques (Bobbert et al., 1996; Bobbert \& Casius, 2005). In the very early stages of knee extension, whilst the total length of the knee extensor musculo-tendon units decrease, the contractile elements may still be being stretched as the tendon begins its elastic recoil and so knee extension begins with large eccentric muscle forces (Alexander, 1995). All of 
these factors reduce the importance of fast initial rate of torque development during CMJs.

The association between later (post-50 ms) rate of torque development and CMJ height is dependent on absolute maximal force (Tillin et al., 2013) and so with peak isometric knee extension torque already included in the stepwise regressions, the inclusion of the later isometric rates of torque development did not significantly improve the prediction of jump height. Previous studies have used correlation coefficients rather than stepwise regressions to assess the rate of torque development-jump height relationship and so were not affected by this issue (De Ruiter et al., 2006; Marcora \& Miller, 2000; McLellan et al., 2011; Thompson et al., 2013; Tillin et al., 2013). These assertions are further supported by a significant correlation between peak isometric torque and $R_{T D} D_{100-150}(r=0.546 ; P=0.01)$ in the present study.

The significant quadratic relationship between $\mathrm{CMJ} \mathrm{RTD}_{0-50}$ and CMJ height $(r=$ $0.68, \mathrm{P}<0.01)$ was explained by a significant $(r=-0.48, \mathrm{P}<0.05)$ negative correlation between $\mathrm{CMJ} \mathrm{RTD}_{0-50}$ (variable $x$ ) and the knee extension torque at concentric onset (variable $y$ ). This relationship takes the form $x+$ ay $\approx$ constant (i.e. there is a trade-off between the two variables), with $\left(x^{2}+y^{2}\right)$ positively correlating to CMJ height $\left(r=0.69\right.$, adjusted $\left.R^{2}=0.45, P<0.01\right)$. This $\left(x^{2}+y^{2}\right)$ relationship means that the higher jumpers either produced high eccentric knee extension torques (greater y; resulting in an apparent benefit of negative rates of torque development as torque subsequently decreased during knee extension) or were able to maintain their knee extension torque during early concentric contraction (greater $x$ ), with those participants in the mid-range for both variables (neither high $x$ nor high $y$ ) achieving the lowest jump heights.

Despite the discussed benefits of the countermovement phase, the minimum knee and ankle angles were not included in the stepwise solutions. This is in contrast with previous findings that increased knee and ankle joint ranges of motion result in greater jump heights (Georgios et al., 2007; Moran and Wallace, 2007). Further analysis of individual subject data in the present study showed that the highest jumper was the participant with the greatest knee flexion. In theory there is no limit to the relationship between increased squat depth and increased squat jump height (Domire \& Challis, 2007); however, jumps from a deep squat are rarely optimally coordinated due to a lack of practice with this technique. This same issue is likely present in inexperienced countermovement jumpers and may explain why the link between minimum knee angle and CMJ height was only observed in the best performing participant.

Previous studies have simply compared jumps with and without an arm swing (Feltner et al., 1999; Harman et al., 1990; Payne et al., 1968; Shetty \& Etnyre, 1989; Vanezis \& Lees, 2005), whereas the present study investigated shoulder angles at key points in the arm swing movement. Greater shoulder flexion at take-off was a strong predictor of CMJ height, likely indicating greater use of the arm swing, and thus a slowing of hip extension leading to greater work done at the hip as well as the shoulder (Blache \& Monteil, 2013; Cheng et al., 2008; Domire \& Challis, 2010). Both greater shoulder flexion and ankle plantar-flexion at take-off increase the 'stretch height' and thus pre-takeoff displacement and both were included in the CMJ kinematic regression. Because CMJ height was calculated relative to standing position, pre-takeoff displacement was included and thus jump height may be affected by anthropometric variables such as foot length. However, the degree to which any anthropometric advantage is reflected in the stretch height is dependent 
on technique such as shoulder flexion and ankle plantar-flexion. An analysis of individual participant data suggests that the degree of ankle plantar-flexion and shoulder flexion during the propulsion phase distinguishes the highest two jumpers from the rest of the participants and explains the underestimation of their jump heights by the CMJ kinetic and isometric parameter regression models. Exclusion of these participants would increase the adjusted $R^{2}$ for these two regressions to 0.66 and 0.40 respectively, illustrating the importance of recruiting a heterogeneous sample so as not to overestimate the importance of individual factors in the progression from poor to good countermovement jumping.

One limitation of the present study is the introduction of errors by any movement outside of the sagittal plane, although this is expected to have been negligible. Furthermore, isometric knee extensions were measured at five discrete joint angles and so the true peak isometric torque is likely at an intermediate angle. In a review by Jakobi and Chilibeck (2001) 5 out of 8 studies showed no bilateral deficit in isometric knee extension. The effect is present, however, in explosive voluntary contractions such as the isometric rate of torque development trials in this study (Buckthorpe, Pain, \& Folland, 2013). The potential implications of this deficit in the present study are minor, with the application of unilateral measures to the investigation of a bilateral performance task unlikely to distort the observed relationships. The $74 \%$ of $\mathrm{CMJ}$ height variation explained by the overall three parameter regression suggests that the important aspects of performance have been identified. In particular, those wishing to improve their CMJ height should seek to maximise power at the knee and ankle joints and utilise greater ankle plantar-flexion and shoulder flexion. These results are likely to provide a valuable framework upon which to base coaching and conditioning as athletes progress from poor to good countermovement jumping. Future studies should continue to explore the interaction between kinetic and kinematic factors, including joint ranges of motion and the timings of muscle activations, possibly using methods beyond the scale of the current study such as simulation modelling or electromyography. It is also important to address whether these results are independent of anthropometric differences and whether the same results are observed in a female population.

In conclusion, the purpose of the study was to quantify the relative contributions of kinetic and kinematic parameters in order to identify the most important determinants of CMJ performance. The findings suggest that both kinetic and kinematic factors during the jump are important determinants of CMJ performance, with technique influencing the extent to which maximal muscle capabilities can be utilised during the jump. The study has revealed the importance of lower-limb joint powers and previously underestimated, coachable technique factors including greater ankle plantar-flexion during the jump and shoulder flexion during the arm swing. Both the kinetic and kinematic variables during the jump explained a large proportion of the performance variation and further research is needed to fully understand the interactions between these two sets of factors.

\section{REFERENCES}

Alexander, R.McN. (1995). Leg design and jumping technique for humans, other vertebrates and insects. Philosophical Transactions of the Royal Society B, 347, 235-248.

Andersen, L.L., \& Aagaard, P. (2006). Influence of maximal muscle strength and intrinsic muscle contractile properties on contractile rate of force development. European Journal of Applied Physiology, 96, 46-52. 
Ashley, C.D., \& Weiss, L.W. (1994). Vertical jump performance and selected physiological characteristics of women. Journal of Strength \& Conditioning Research, 8, 5-11.

Blache, Y., \& Monteil, K. (2013). Effect of arm swing on effective energy during vertical jumping: Experimental and simulation study. Scandinavian Journal of Medicine \& Science in Sports, 23, 121-129.

Bobbert, M.F., \& Casius, L.J.R. (2005). Is the effect of a countermovement on jump height due to active state development? Medicine and Science in Sports and Exercise, 37, 440-446.

Bobbert, M.F., Casius, L.J.R., Sijpkens, I.W.T., \& Jaspers, R.T. (2008). Humans adjust control to initial squat depth in vertical jumping. Journal of Applied Physiology, 105, 1428-1440.

Bobbert, M.F., Gerritsen, K.G.M., Litjens, M.C.A., \& Van Soest, A.J. (1996). Why is countermovement jump height greater than squat jump height? Medicine and Science in Sports and Exercise, 28, 1402-1412.

Bobbert, M.F., \& Van Soest, A.J. (1994). Effects of muscle strengthening on vertical jump height: a simulation study. Medicine and Science in Sports and Exercise, 26, 1012-1020.

Bowerman, B.L., \& O'Connell, R.T. (1990). Linear statistical models: An applied approach (2nd ed.). Belmont, CA: Duxbury.

Buckthorpe, M.W., Pain, M.T.G., \& Folland, J.P. (2013). Bilateral deficit in explosive force production is not caused by changes in agonist neural drive. PLOS ONE, 8, e57549.

Cheng, K.B., Wang, C., Chen, H., Wu, C., \& Chiu, H. (2008). The mechanisms that enable arm motion to enhance vertical jump performance-A simulation study. Journal of Biomechanics, 41, 1847-1854.

Clutch, D., Wilton, M., McGown, C., \& Bryce, G.R. (1983). The effect of depth jumps and weight training on leg strength and vertical jump. Research Quarterly for Exercise and Sport, 54, 5-10.

Davis, R.B., Õunpuu, S., Tyburski, D., \& Gage, J.R. (1991). A gait analysis data collection and reduction technique. Human Movement Science, 10, 575-587.

De Ruiter, C.J., Van Leeuwen, D., Heijblom, A., Bobbert, M.F., \& De Haan, A. (2006). Fast unilateral isometric knee extension torque development and bilateral jump height. Medicine and Science in Sports \& Exercise, 38, 1843-1852.

Domire, Z.J., \& Challis, J.H. (2007). The influence of squat depth on maximal vertical jump performance. Journal of Sports Sciences, 25, 193-200.

Domire, Z.J., \& Challis, J.H. (2010). An induced energy analysis to determine the mechanism for performance enhancement as a result of arm swing during jumping. Sports Biomechanics, 9, 38-46.

Draper, N.R., \& Smith, H. (1998). Applied regression analysis (3rd ed.). New York, NY: Wiley.

Edman, K.A.P., Elzinga, G., \& Noble, M.I.M. (1978). Enhancement of mechanical performance by stretch during tetanic contractions of vertebrate skeletal muscle fibres. Journal of Physiology, 281, 139-155. 
Feltner, M.E., Fraschetti, D.J., \& Crisp, R.J. (1999). Upper extremity augmentation of lower extremity kinetics during countermovement vertical jumps. Journal of Sports Sciences, 17, 449-466.

Field, A.P. (2013). Discovering statistics using IBM SPSS Statistics (4th ed.). London: Sage.

Fukashiro, S., \& Komi, P.V. (1987). Joint moment and mechanical power flow of the lower limb during vertical jump. International Journal of Sports Medicine, 8, 15-21.

Georgios, P., Fotis, K., Thomas, N., Vassilios, P., \& Iraklis, K. (2007). Influence of the ankle joint dorsiflexion on the execution of vertical jumps. In ISBS-Conference Proceedings Archive (Vol. 1, No. 1).

Hara, M., Shibayama, A., Takeshita, D., \& Fukashiro, S. (2006). The effect of arm swing on lower extremities in vertical jumping. Journal of Biomechanics, 39, 25032511.

Harman, E.A., Rosenstein, M.T., Frykman, P.N., \& Rosenstein, R.M. (1990). The effects of arms and countermovement on vertical jumping. Medicine and Science in Sports and Exercise, 22, 825-833.

Hubley, C.L., \& Wells, R.P. (1983). A work-energy approach to determine individual joint contributions to vertical jump performance. European Journal of Applied Physiology, 50, 247-254.

Jakobi, J.M., \& Chilibeck, P.D. (2001). Bilateral and unilateral contractions: Possible differences in maximal voluntary force. Canadian Journal of Applied Physiology, 26, 12-33.

Lees, A., Vanrenterghem, J., \& De Clercq, D. (2004). Understanding how an arm swing enhances performance in the vertical jump. Journal of Biomechanics, 37, 1929-1940.

Luhtanen, P., \& Komi, P.V. (1978). Segmental contribution to forces in vertical jump. European Journal of Applied Physiology, 38, 181-188.

Marcora, S., \& Miller, M.K. (2000). The effect of knee angle on the external validity of isometric measures of lower body neuromuscular function. Journal of Sports Sciences, 18, 313-319.

McLellan, C.P., Lovell, D.I., \& Gass, G.C. (2011). The role of rate of force development on vertical jump performance. Journal of Strength and Conditioning Research, 25, 379-385.

Menard, S. (1995). Applied logistic regression analysis: Sage University series on quantitative applications in the social sciences. Thousand Oaks, CA: Sage.

Moran, K.A., \& Wallace, E.S. (2007). Eccentric loading and range of knee joint motion effects on performance enhancement in vertical jumping. Human Movement Science, 26, 824-840.

Myers, R. (1990). Classical and modern regression with applications (2nd ed.). Boston, MA: Duxbury.

Nuzzo, J.L., McBride, J.M., Cormie, P., \& McCaulley, G.O. (2008). Relationship between countermovement jump performance and multijoint isometric and dynamic tests of strength. Journal of Strength \& Conditioning Research, 22, 699707. 
Payne, A.H., Slater, W.J., \& Telford, T. (1968). The use of a force platform in the study of athletic activities. Ergonomics, 11, 123-143.

Ranson, C., King, M., Burnett, A., Worthington, P., \& Shine, K. (2009). The effect of coaching intervention on elite fast bowling technique over a two year period. Sports Biomechanics, 8, 261-274.

Read, M.M., \& Cisar, C. (2001). The influence of varied rest interval lengths on depth jump performance. Journal of Strength and Conditioning Research, 15, 279-283.

Sahaly, R., Vandewalle, H., Driss, T., \& Monod, H. (2001). Maximal voluntary force and rate of force development in humans - importance of instruction. European Journal of Applied Physiology, 85, 345-350.

Sheppard, J.M., Cronin, J.B., Gabbett, T.J., McGuigan, M.R., Etxebarria, N., \& Newton, R.U. (2008). Relative importance of strength, power, and anthropometric measures to jump performance of elite volleyball players. Journal of Strength \& Conditioning Research, 22, 758-765.

Shetty, A.B., \& Etnyre, B.R. (1989). Contribution of arm movement to the force components of a maximum vertical jump. The Journal of Orthopaedic and Sports Physical Therapy, 11, 198-201.

Thompson, B.J., Ryan, E.D., Sobolewski, E.J., Smith, D.B., Akehi, K., Conchola, E.C., \& Buckminster, T. (2013). Relationships between rapid isometric torque characteristics and vertical jump performance in Division I collegiate American football players: influence of body mass normalisation. Journal of Strength and Conditioning Research. Advance Online Publication.

Tillin, N.A., Jimenez-Reyes, P., Pain, M.T.G., \& Folland, J.P. (2010). Neuromuscular performance of explosive power athletes versus untrained individuals. Medicine \& Science in Sports \& Exercise, 42, 781-790.

Tillin, N.A., Pain, M.T.G., \& Folland, J.P. (2012). Short-term training for explosive strength causes neural and mechanical adaptations. Experimental Physiology, 97, 630-641.

Tillin, N.A., Pain, M.T.G., \& Folland, J. (2013). Explosive force production during isometric squats correlates with athletic performance in rugby union players. Journal of Sports Sciences, 31, 66-76.

Vanezis, A., \& Lees, A. (2005). A biomechanical analysis of good and poor performers of the vertical jump. Ergonomics, 48, 1594-1603.

Wherry, R.J. (1931). A new formula for predicting the shrinkage of the coefficient of multiple correlation coefficient. Annals of Mathematical Statistics, 2, 440-451.

Winter, D.A. (1990). Biomechanics and motor control of human movement. New York, NY: Wiley.

Wisløff, U., Castagna, C., Helgerud, J., Jones, R., \& Hoff, J. (2004). Strong correlation of maximal squat strength with sprint performance and vertical jump height in elite soccer players. British Journal of Sports Medicine, 38, 285-288.

Yeadon, M.R. (1990). The simulation of aerial movement - II. A mathematical inertia model of the human body. Journal of Biomechanics, 23, 67-74.

Young, W., Wilson, G., \& Byrne, C. (1999). Relationship between strength qualities and performance in standing and run-up vertical jumps. The Journal of Sports Medicine and Physical Fitness, 39, 285-293. 